\title{
Functional-Based Auto-Tuned IC Engine
}

\author{
Amirzubir Sahamijoo ${ }^{1}$,Farzin Piltan ${ }^{1}$,Shahnaz Tayebihaghighi ${ }^{1}$ and Nasri b \\ Sulaiman $^{1-2}$ \\ ${ }^{1}$ Intelligent System and Robotic Lab, Iranian Institute of Advanced Science and \\ Technology (IRAN SSP), Shiraz/Iran \\ ${ }^{2}$ Department of Electrical and Electronic Engineering, Faculty of Engineering, \\ University Putra Malaysia, Malaysia \\ piltan_f@iranssp.org,WWW.IRANSSP.org/english
}

\begin{abstract}
One of the most familiar challenge of air pollution over the cities is smog hanging. The effects of inhaling particulate matter have been studied in humans and animals and include asthma, lung cancer, cardiovascular issues, and premature death. There are, however, some additional products of the combustion process that include nitrogen oxides and sulfur and some un-combusted hydrocarbons, depending on the operating conditions and the fuel-air ratio. one of the important parameters to the control of lung cancer in big cities around the world is tuning the fuel to air ratio. To tuning the fuel to air ratio, functional based nonlinear controller is introduced. A mathematical function is used to improve the performance of the tuning the fuel to air ratio.
\end{abstract}

Keywords: smog hanging, air pollution, lung cancer, IC Engine, fuel-air ratio, functional based-control

\section{System (Internal Combustion Engine)}

Smog hanging over cities is the most familiar and obvious form of air pollution. But there are different kinds of pollution-some visible, some invisible - that contribute to global warming. Generally any substance that people introduce into the atmosphere that has damaging effects on living things and the environment is considered air pollution. Carbon dioxide, a greenhouse gas, is the main pollutant that is warming Earth. Though living things emit carbon dioxide when they breathe, carbon dioxide is widely considered to be a pollutant when associated with cars, planes, power plants, and other human activities that involve the burning of fossil fuels such as gasoline and natural gas. In the past 150 years, such activities have pumped enough carbon dioxide into the atmosphere to raise its levels higher than they have been for hundreds of thousands of years. Other greenhouse gases include methane-which comes from such sources as swamps and gas emitted by livestock - and chlorofluorocarbons (CFCs), which were used in refrigerants and aerosol propellants until they were banned because of their deteriorating effect on Earth's ozone layer. Another pollutant associated with climate change is sulfur dioxide, a component of smog. Sulfur dioxide and closely related chemicals are known primarily as a cause of acid rain. But they also reflect light when released in the atmosphere, which keeps sunlight out and causes Earth to cool [1-3]. Modeling of an entire internal combustion (IC) engine is a very important and complicated process because internal combustion engines are nonlinear, multi inputs-multi outputs (MIMO) and time variant. There have been several engine controller designs over the previous years in which the main goal is to improve the efficiency and exhaust emissions of the automotive engine [5-7]. Specific applications of air to fuel (A/F) ratio control based on observer measurements in the intake manifold were developed by Benninger in 1991 [8]. Another approach was to base the observer on measurements of exhaust gases measured by the 
oxygen sensor and on the throttle position, which was researched by Onder. These observer ideas used linear observer theory. Hedrick also used the measurements of the oxygen sensor to develop a nonlinear, sliding mode approach to control the $\mathrm{A} / \mathrm{F}$ ratio [9]. All of the previous control strategies were applied to engines that used only port fuel injections, where fuel was injected in the intake manifold. Current production $\mathrm{A} / \mathrm{F}$ ratio controllers use closed loop feedback and feed forward control to achieve the desired stoichio metric mixture. These controllers use measurements from the oxygen sensor to control the desired amount of fuel that should be injected over the next engine cycle and have been able to control the A/F very well. In developing a valid engine model, the concept of the combustion process, abnormal combustion, and cylinder pressure must be understood. The combustion process is relatively simple and it begins with fuel and air being mixed together in the intake manifold and cylinder. This air-fuel mixture is trapped inside cylinder after the intake valve(s) is closed and then gets compressed. When the airfuel mixture is compressed it causes the pressure and temperature to increase inside the cylinder. Unlike normal combustion, the cylinder pressure and temperature can rise so rapidly that it can spontaneously ignite the air-fuel mixture causing high frequency cylinder pressure oscillations. These oscillations cause the metal cylinders to produce sharp noises called knock, which it caused to abnormal combustion. The pressure in the cylinder is a very important physical parameter that can be analyzed from the combustion process. After the flame is developed, the cylinder pressure steadily rises, reaches a maximum point after TDC, and finally decreases during the expansion stroke when the cylinder volume increases. Since cylinder pressure is very important to the combustion event and the engine cycle in spark ignition engines, the development of a model that produces the cylinder pressure for each crank angle degree is necessary. Regarding to IC engine modeling, it is important to design nonlinear model-reference controller. In developing a valid engine model, the concept of the combustion process, abnormal combustion and cylinder pressure must be understood. The combustion process is relatively simple and it begins with fuel and air being mixed together in the intake manifold and cylinder. This air-fuel mixture is trapped inside cylinder after the intake valve(s) is closed and then gets compressed. When the air-fuel mixture is compressed it causes the pressure and temperature to increase inside the cylinder. In abnormal combustion, the cylinder pressure and temperature can rise so rapidly that it can spontaneously ignite the air-fuel mixture causing high frequency cylinder pressure oscillations. These oscillations cause the metal cylinders to produce sharp noises called knock, which it caused to abnormal combustion. The pressure in the cylinder is a very important physical parameter that can be analyzed from the combustion process. Since cylinder pressure is very important to the combustion event and the engine cycle in spark ignition engines, the development of a model that produces the cylinder pressure for each crank angle degree is necessary. The dynamic equations of IC engine can be written as:

$$
\begin{aligned}
& {\left[\begin{array}{c}
P F I \\
D I
\end{array}\right]=\left[\begin{array}{ll}
\dot{M}_{\text {air } 11} & \dot{M}_{\text {air } 12} \\
\dot{M}_{\text {air } 21} & \dot{M}_{\text {air } 22}
\end{array}\right]\left[\begin{array}{c}
\ddot{F R} \\
\ddot{\alpha}_{I}
\end{array}\right]+\left[\begin{array}{l}
P_{\text {motor }_{1}} \\
P_{\text {motor }_{2}}
\end{array}\right]\left[\begin{array}{ll}
\dot{F R} & \dot{\alpha}_{I}
\end{array}\right]+\left[\begin{array}{ll}
N_{11} & N_{12} \\
N_{21} & N_{22}
\end{array}\right] \times} \\
& {\left[\begin{array}{c}
\dot{F R} \\
\dot{\alpha}_{I}
\end{array}\right]^{2}+\left[\begin{array}{l}
M_{a_{1}} \\
M_{a_{2}}
\end{array}\right]}
\end{aligned}
$$

There for to calculate the fuel ratio and equivalence ratio we can write:

$$
\begin{aligned}
& {\left[\begin{array}{c}
F \ddot{R}_{a} \\
\ddot{\alpha}_{I_{a}}
\end{array}\right]=\left[\begin{array}{ll}
\dot{M}_{\text {air } 11} & \dot{M}_{\text {air } 12} \\
\dot{M}_{\text {air }} & \dot{M}_{\text {air }_{22}}
\end{array}\right]^{-1}\left\{\left[\begin{array}{c}
P F I \\
D I
\end{array}\right]-\left\{\left[\begin{array}{l}
P_{\text {motor }_{1}} \\
P_{\text {motor }_{2}}
\end{array}\right]\left[\begin{array}{ll}
F R & \dot{\alpha}_{I_{a}}
\end{array}\right]+\left[\begin{array}{ll}
N_{11} & N_{12} \\
N_{21} & N_{22}
\end{array}\right] \times\right.\right.} \\
& \left.\left.\left[\begin{array}{c}
F \dot{R}_{a} \\
\dot{\alpha}_{I_{a}}
\end{array}\right]^{2}+\left[\begin{array}{c}
M_{a_{1}} \\
M_{a_{2}}
\end{array}\right]\right\}\right\}
\end{aligned}
$$

To solve $\dot{\boldsymbol{M}}_{\text {air }}$, 


$$
\dot{M}_{\text {air }}=\left[\begin{array}{ll}
\dot{M}_{\text {air } 11} & \dot{M}_{\text {air } 12} \\
\dot{M}_{\text {air } 21} & \dot{M}_{\text {air } 22}
\end{array}\right] \quad \text { Where } \dot{M}_{\text {air } 12}=\dot{M}_{\text {air } 21}
$$

Where $\dot{\boldsymbol{M}}_{\boldsymbol{a i r}}$ is the ratio of the mass of air.

Matrix $P_{\text {motor }}$ is a $1 \times 2$ matrix:

$$
P_{\text {motor }}=\left[\begin{array}{l}
\boldsymbol{P}_{1} \\
\boldsymbol{P}_{2}
\end{array}\right]
$$

Matrix engine angular speed matrix $(N)$ is a $2 \times 2$ matrix

$$
N=\left[\begin{array}{ll}
N_{11} & N_{12} \\
N_{21} & N_{22}
\end{array}\right]
$$

Where,

Matrix mass of air in cylinder for combustion matrix $\left(M_{a}\right)$ is a $1 \times 2$ matrix.

$$
M_{a}=\left[\begin{array}{l}
\boldsymbol{M}_{a_{1}} \\
\boldsymbol{M}_{a_{2}}
\end{array}\right]
$$

The above target equivalence ratio calculation will be combined with fuel ratio calculation that will be used for controller design purpose. Figure 1 shows the IC engine.

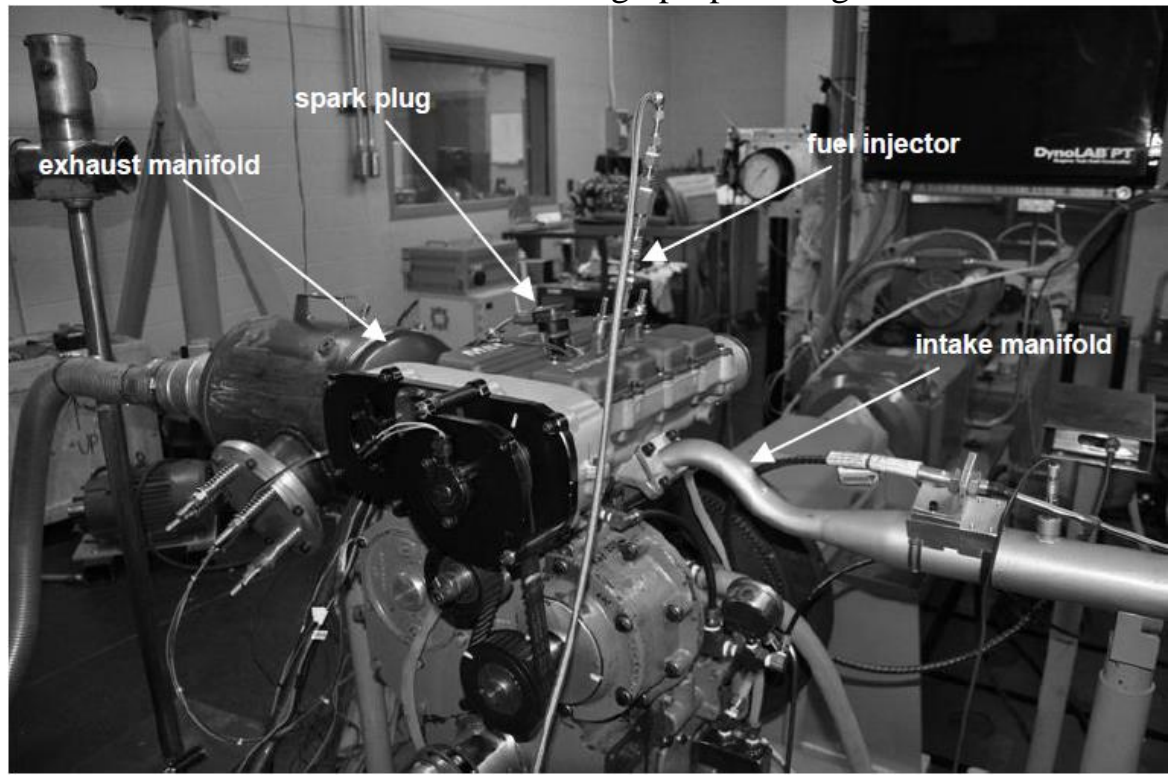

Figure 1. Test Engine

\section{Linear Control Technique (LCT)}

Linear control theory is used in linear and nonlinear systems. This type of theory is used in industries, because design of this type of controller is simple than nonlinear controller. However this type of controller used in many applications but it cannot guarantee performance in complex systems. Proportional $(\mathrm{P})$ control is used to responds immediately to difference of control input variables by immediately changing its influences variables, but this type of control is unable to eliminate the control input difference.

Proportional plus Derivative (PD) controller is widely used in control process where the results are sensitive to exceeded of set point. This controller, like Proportional controller, has permanent variation in presence of self-limitation control. In mathematically, the formulation of Proportional-Derivative part calculated as follows;

$U_{P D}=K_{p} \times e+K_{v}\left(\frac{d e}{d t}\right)=K_{p} \times e+K_{v} \dot{e}$ 
The Derivative component in this type of methodology is used to cancel outs the change process variables change in presence of quick change in controllers input.

To test the quality of PD controller, two parameters are test, namely, $\alpha$ and fuel ratio. Figure 2, shows the $\alpha$ trajectory test. According to this Figure, we have steady stable error.

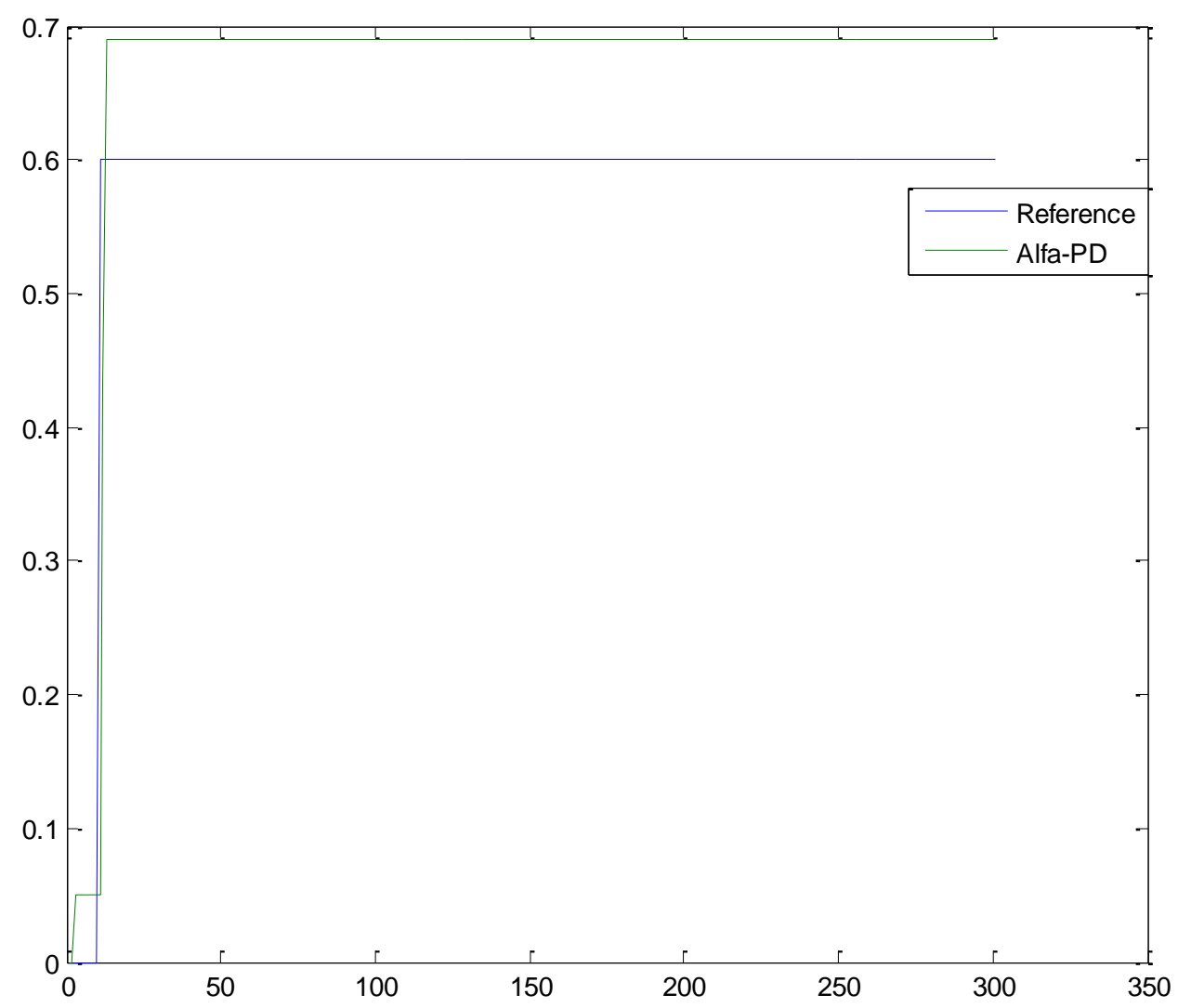

Figure 2. Test Alfa Parameters in IC Engine in PD Controller

Figure 3, shows the rate of fuel ratio. The reference number for fuel ratio equal to 0.6 and PD control algorithm cannot guarantee the quality this performance. 


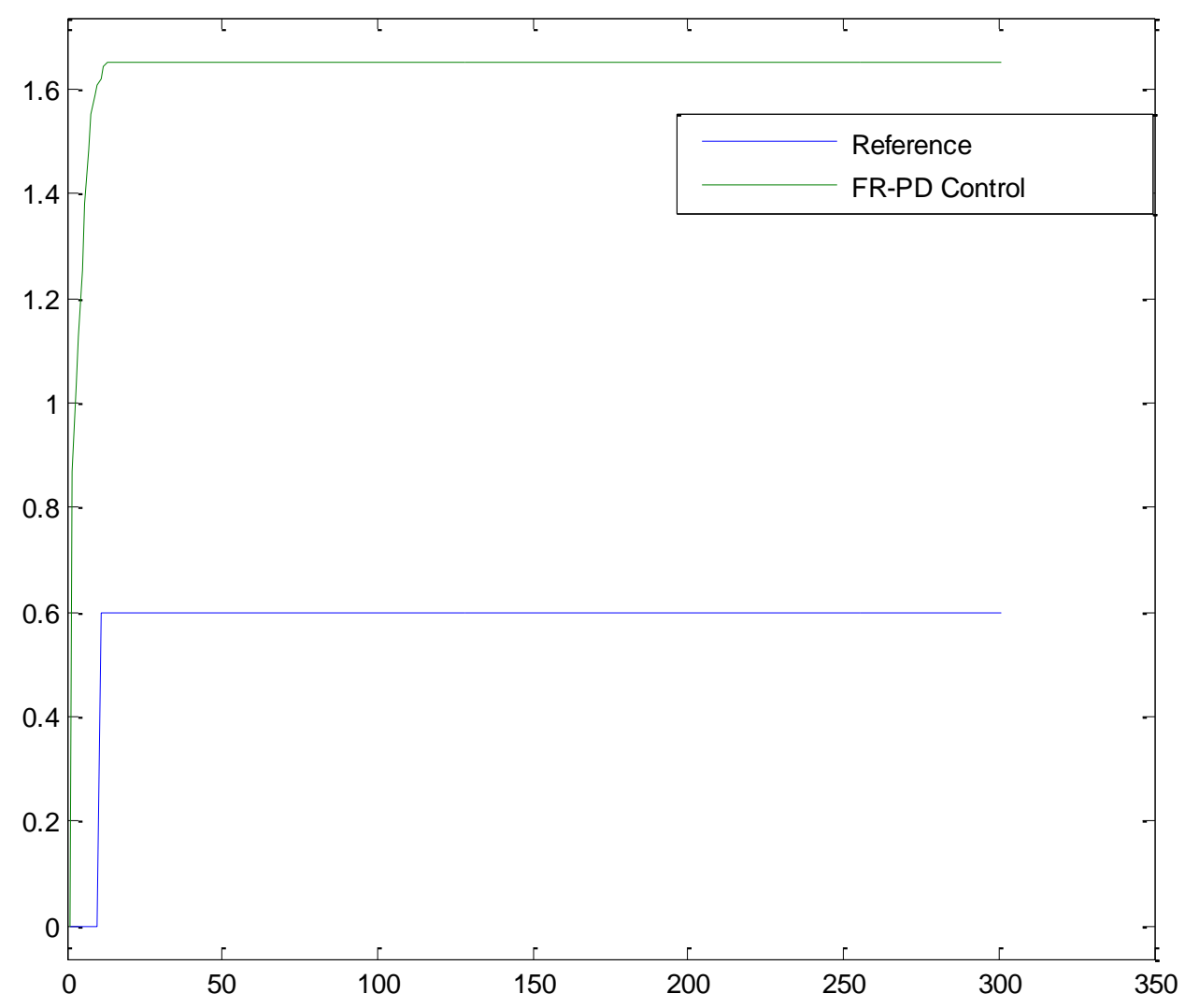

Figure 3. Test Fuel Ratio Parameters in IC Engine in PD Controller

In this research to have the best efficiency, we assume that the fuel ratio equal to 0.6 . After test it, the rate of fuel ratio in PD control technique is equal to 1.7.

\section{Fuctional Based Auto Tuned IC Engine}

Functional based controller (FBC) is one of the nonlinear controllers in a partly uncertain dynamic system's parameters. The main idea to design FBC is based on the following formulation;

$\boldsymbol{U}_{(t)}= \begin{cases}\boldsymbol{U}_{i}^{+}(\boldsymbol{t}) & \text { if } \boldsymbol{S}_{\boldsymbol{i}}>0 \\ \boldsymbol{U}_{\boldsymbol{i}}^{-}(\boldsymbol{t}) & \text { if } \boldsymbol{S}_{\boldsymbol{i}}<0\end{cases}$

where $\boldsymbol{S}_{\boldsymbol{i}}$ is sliding surface (switching surface), $\boldsymbol{i}=\mathbf{1}, \mathbf{2}, \ldots \ldots, \boldsymbol{n}$ for $n$ input/output system, $\boldsymbol{U}_{\boldsymbol{i}}(\boldsymbol{t})$ is the $\boldsymbol{i}^{\boldsymbol{t h}}$ system's output. The dynamic formulation of nonlinear single input system is defined by:

$x^{(n)}=f(\vec{x})+b(\vec{x}) u$

$\boldsymbol{u}$ is the vector of control input, $\boldsymbol{x}^{(\boldsymbol{n})}$ is the $\boldsymbol{n}^{\text {th }}$ derivation of $\boldsymbol{x}, \boldsymbol{x}=\left[\boldsymbol{x}, \dot{\boldsymbol{x}}, \ddot{\boldsymbol{x}}, \ldots, \boldsymbol{x}^{(\boldsymbol{n}-1)}\right]^{\boldsymbol{T}}$ is the state vector, $\boldsymbol{f}(\boldsymbol{x})$ is unknown or uncertainty, and $\boldsymbol{b}(\boldsymbol{x})$ is known switching (SIGN) function. The main target to design FBC is high speed train and high tracking accuracy to the desired inputs; $\boldsymbol{x}_{\boldsymbol{d}}=\left[\boldsymbol{x}_{\boldsymbol{d}}, \dot{\boldsymbol{x}}_{\boldsymbol{d}}, \ddot{\boldsymbol{x}}_{\boldsymbol{d}}, \ldots, \boldsymbol{x}_{\boldsymbol{d}}^{(\boldsymbol{n}-\mathbf{1})}\right]^{\boldsymbol{T}}$, according to actual and desired inputs/outputs, the trucking error vector is defined by: 
$\widetilde{x}=x_{d}-x_{a}=\left[\widetilde{x}, \ldots, \widetilde{x}^{(n-1)}\right]^{T}$

According to the FBC theory, the main important part to design this controller is sliding surface, a time-varying sliding surface $\boldsymbol{s}(\boldsymbol{x}, \boldsymbol{t})$ in the state space $\boldsymbol{R}^{\boldsymbol{n}}$ is given by the following formulation [4]:

$s(x, t)=\left(\frac{d}{d t}+\lambda\right)^{n-1} \tilde{x}=0$

$\lambda$ is the sliding surface slope coefficient and it is positive constant. The sliding surface can be defined as Proportional-Derivative (PD), Proportional-Integral (PI) and the Proportional-Integral-Derivative (PID). The following formulations represented the three groups are:

$S_{P D}=\lambda e+\dot{e}$

$s(x, t)=\left(\frac{d}{d t}+\lambda\right)^{n-1}\left(\int_{0}^{t} \tilde{x} d t\right)=0$

$S_{P I}=\lambda e+\left(\frac{\lambda}{2}\right)^{2} \sum e$

$S_{P I D}=\lambda e+\dot{e}+\left(\frac{\lambda}{2}\right)^{2} \sum e$

Integral part of sliding surface is used to decrease the steady state error in FBC. To have the stability and minimum error in FBC, the main objective is kept the sliding surface slope $s(x, t)$ near to the zero. Therefore, one of the common strategies is to find input $U$ outside of $s(x, t)$.

$\frac{1}{2} \frac{d}{d t} s^{2}(x, t) \leq-\zeta|s(x, t)|$

$\zeta$ is positive constant.

If $S(0)>0 \rightarrow \dot{S}(t) \leq-\zeta$

The derivative term of $(\boldsymbol{s})$ is eliminated by limited integral from $\mathrm{t}=0$ to $\mathrm{t}=\boldsymbol{t}_{\text {reach }}$

$\int_{t=0}^{t=t_{\text {reach }}} \dot{S}(t) \leq-\int_{t=0}^{t=t_{\text {reach }}} \eta \rightarrow S\left(t_{\text {reach }}\right)-S(0) \leq-\zeta\left(t_{\text {reach }}-0\right)$

The $t_{\text {reach }}$ is the time that trajectories reach to the sliding surface. If $\boldsymbol{S}_{\boldsymbol{t}_{\text {reach }}}=\mathbf{0}$ the formulation of $\boldsymbol{t}_{\text {reach }}$ calculated by;

$0-S(0) \leq-\eta\left(t_{\text {reach }}\right) \rightarrow t_{\text {reach }} \leq \frac{S(0)}{\zeta}$

If $\boldsymbol{S}(\mathbf{0})<0$

$0-S(\mathbf{0}) \leq-\eta\left(\boldsymbol{t}_{\text {reach }}\right) \rightarrow \boldsymbol{S}(\mathbf{0}) \leq-\zeta\left(\boldsymbol{t}_{\text {reach }}\right) \rightarrow \boldsymbol{t}_{\text {reach }} \leq \frac{|\boldsymbol{S}(\mathbf{0})|}{\boldsymbol{\eta}}$

This formulation is guarantee time to reach the sliding surface is smaller than $\frac{|S(\mathbf{0})|}{\zeta}$ since the trajectories are outside of $S(t)$.

if $S_{t_{\text {reach }}}=S(0) \rightarrow \operatorname{error}\left(x-x_{d}\right)=0$

According to above discussion the formulation of sliding surface $(S)$ is defined as

$s(x, t)=\left(\frac{d}{d t}+\lambda\right) \quad \widetilde{x}=\left(\dot{\mathbf{x}}-\dot{\mathbf{x}}_{\mathbf{d}}\right)+\lambda\left(\mathbf{x}-\mathbf{x}_{\mathbf{d}}\right)$

The change of sliding surface $(\dot{S})$ is;

$\dot{S}=\left(\ddot{\mathrm{x}}-\ddot{\mathrm{x}}_{\mathrm{d}}\right)+\lambda\left(\dot{\mathrm{x}}-\dot{\mathrm{x}}_{\mathrm{d}}\right)$ 
According to the formulation of the second order system, a simple solution to get the sliding condition when the dynamic parameters have uncertainty in parameters or external disturbance is the switching control law:

$U_{F B C}=K(\vec{x}, t) \cdot \operatorname{sgn}(s)$

The switching function $\operatorname{sgn}(\boldsymbol{s})$ is defined as

$\operatorname{sgn}(s)= \begin{cases}1 & s>0 \\ -1 & s<0 \\ 0 & s=0\end{cases}$

Figure 3, shows the application of FBC in fuel ratio. According to the following Figure we have seen that this system has two main challenges, chattering and steady state error. Figure 4, shows the $\alpha$ control applications for IC engine. Based on the Figure 4, however the SIGN based functional based controller used in many applications such as robotics and delay systems but it cannot guarantee the performance of IC engines.

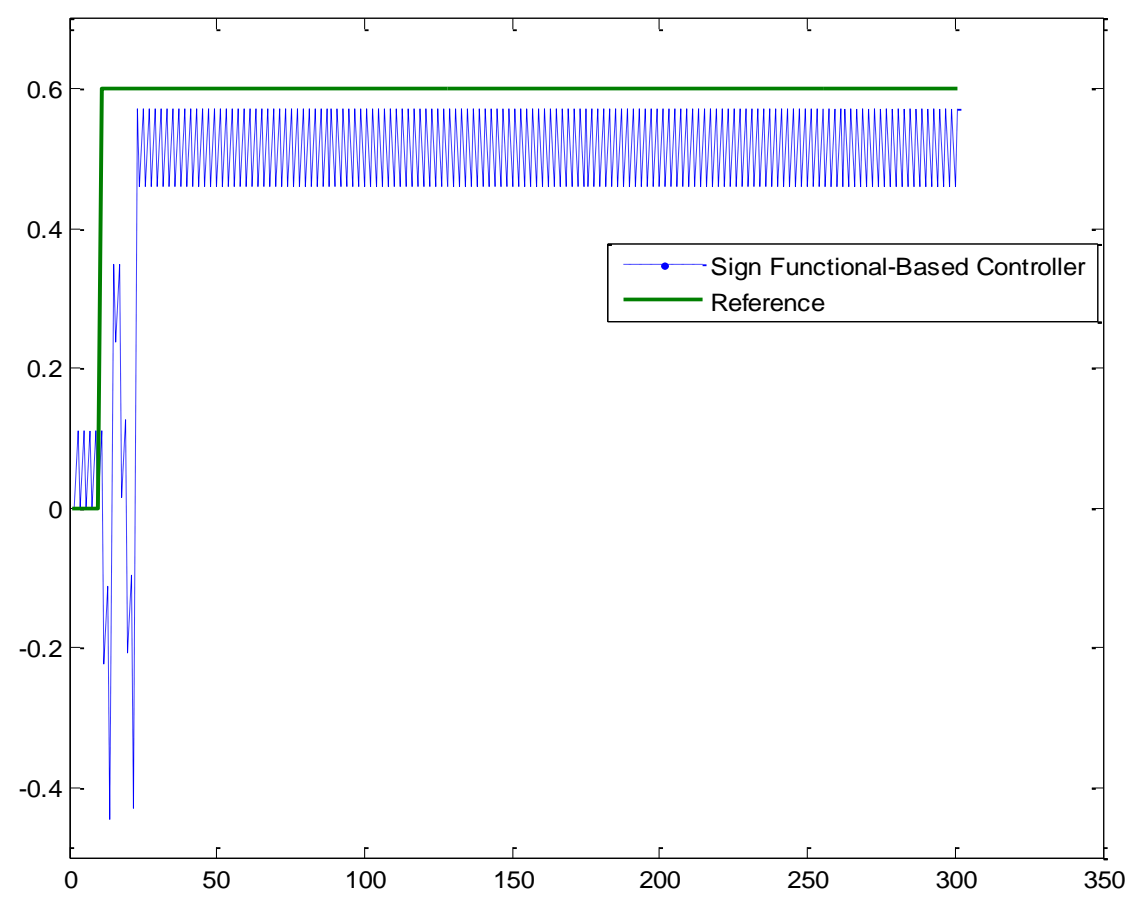

Figure 3. Test Fuel Ratio Parameters in IC Engine in Sign Functional Based Controller 
International Journal of u- and e- Service, Science and Technology

Vol. 9, No. 12 (2016)

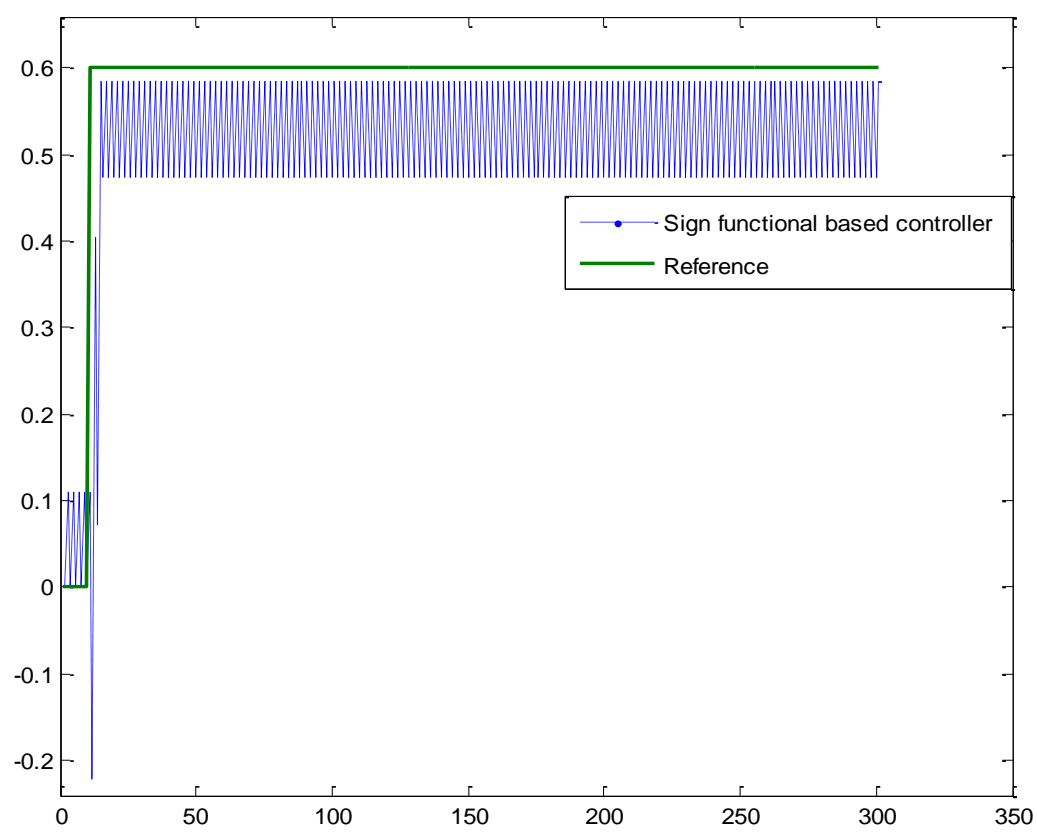

Figure 4. Test ALFA Parameters in IC Engine in Sign Functional Based Controller

Figure 5, shows the speed engine test in functional based controller. The rate of error is less than 0.01 . 


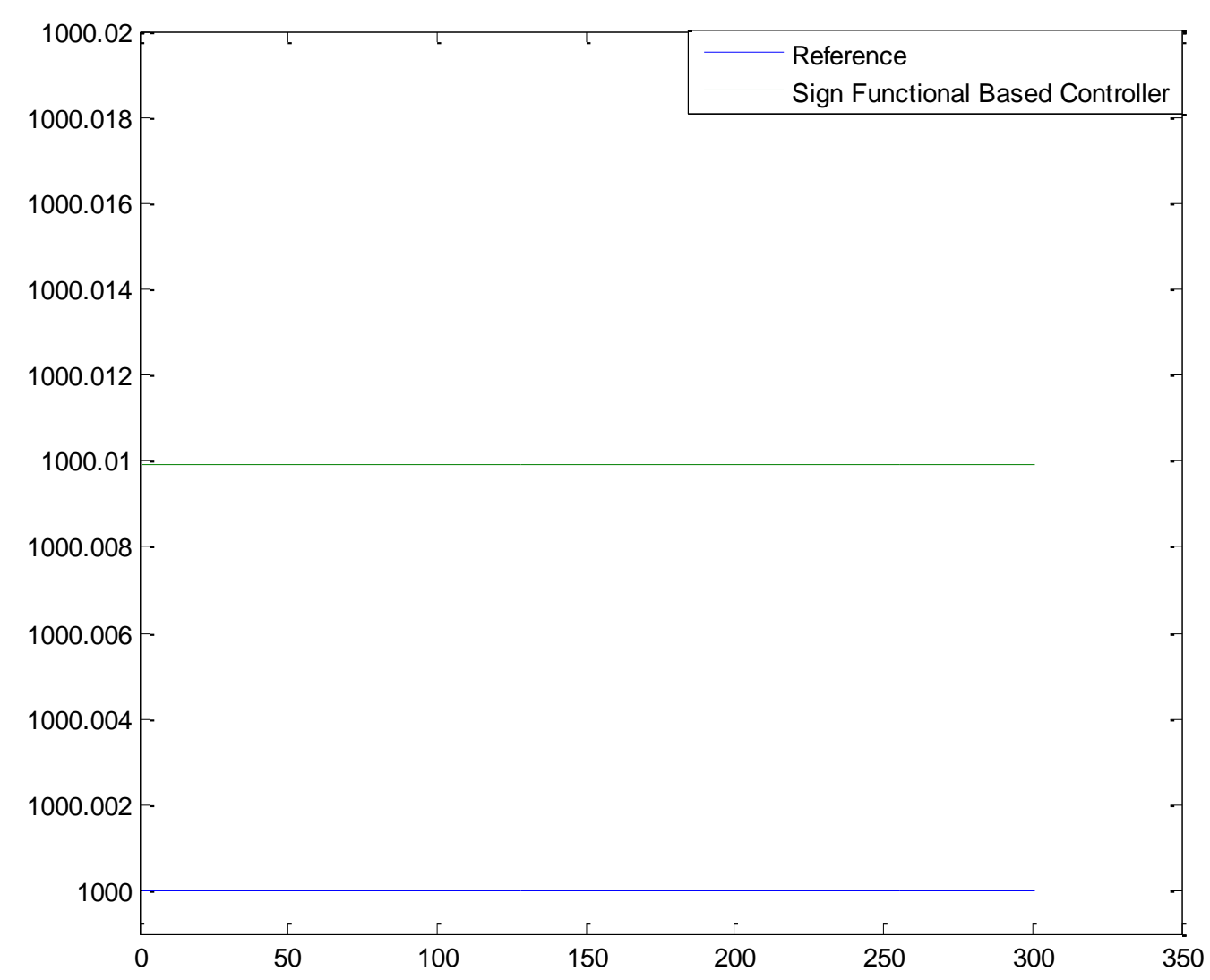

\section{Figure 5. Engine Speed Test in IC Engine in Sign Functional Based Controller}

To improve the performance of functional based controller, saturation functional based controller is introduced. This function is used to reduce or eliminate the oscillations. The saturation (linear) method with small neighborhood of the switching surface is calculated as:

$\boldsymbol{B}(\boldsymbol{t})=\{\boldsymbol{x},|\boldsymbol{S}(\boldsymbol{t})| \leq \emptyset\} ; \varnothing>0$

where $\varnothing$ is the boundary layer thickness. Consequently the FBC can be written by;

$U=K(\vec{x}, t) \cdot \operatorname{Sat}(S / \varnothing)$

While saturation function formulation $(\boldsymbol{S a t}(\mathbf{S} / \varnothing)$ ) is as follows:

$\operatorname{sat}(S / \varnothing)=\left\{\begin{array}{cc}1 & (s / \varnothing>1) \\ -1 & (s / \varnothing<-1) \\ s / \varnothing & (-1<s / \varnothing<1)\end{array}\right.$

Figure 6, shows the application of saturation based FBC to tune the fuel ratio in IC engine. According to Figure 6, saturation function eliminates the error as well as reduces the rate of error. The main challenge in this method is the rise time. The rise time in saturation FBC is about 7 seconds but in sign FBC is about 2.5 seconds. 


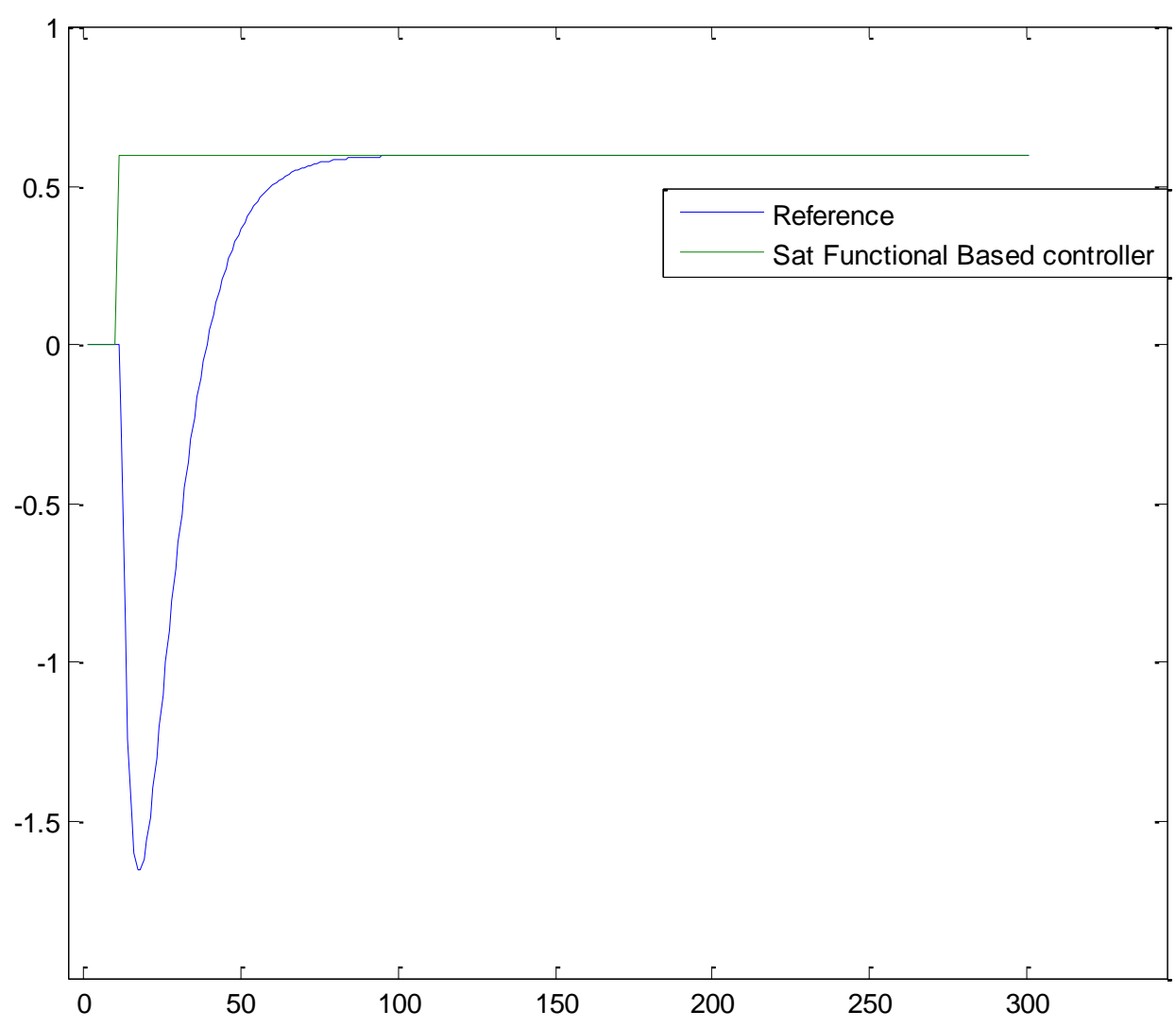

Figure 6. Test Fuel Ratio Parameters in IC Engine in Sat Functional Based Controller

Figure 7, shows the application of saturation FBC in alfa. This methodology eliminates the chattering as well as error and reduces the rise time. Figure 8, shows the engine speed in desired and actual speed. The rate of error in engine speed is less than 0.01 . 


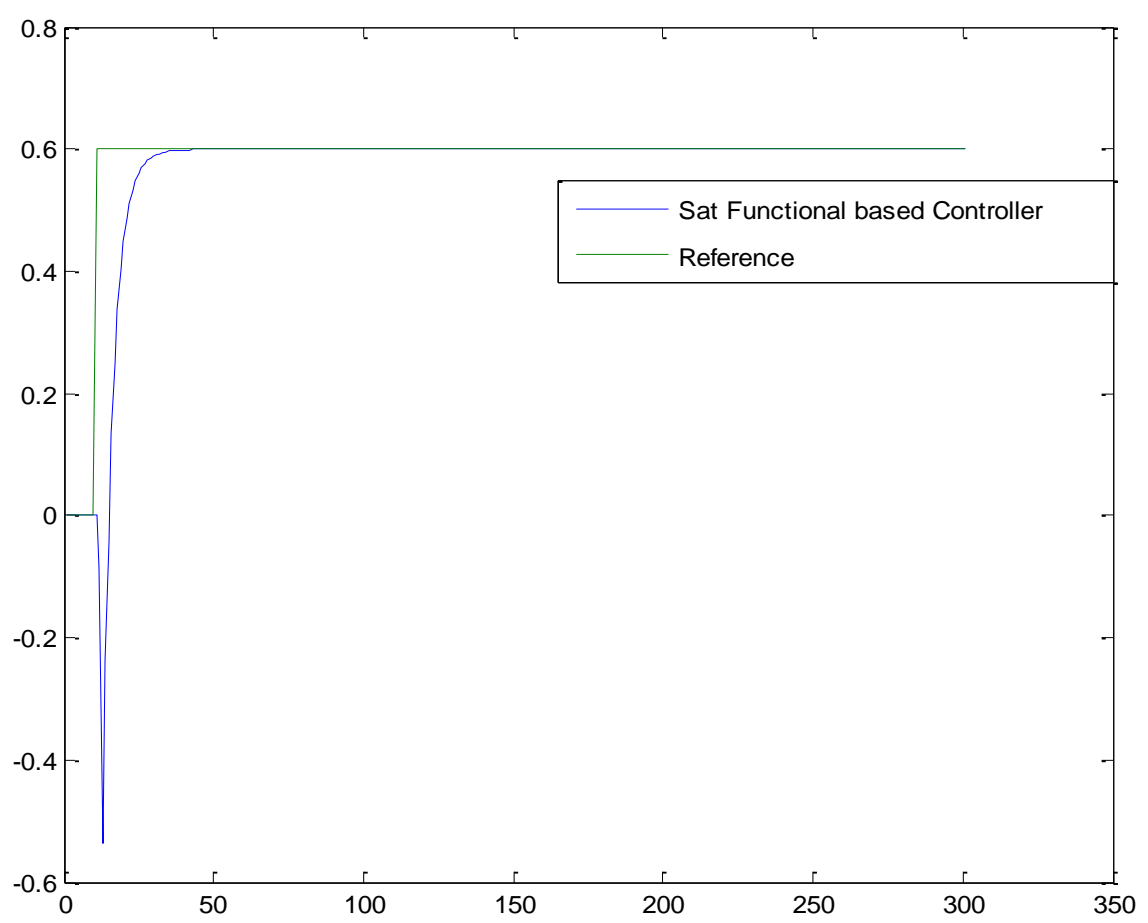

Figure 7. Test Alfa Parameters in IC Engine in Sat Functional Based Controller

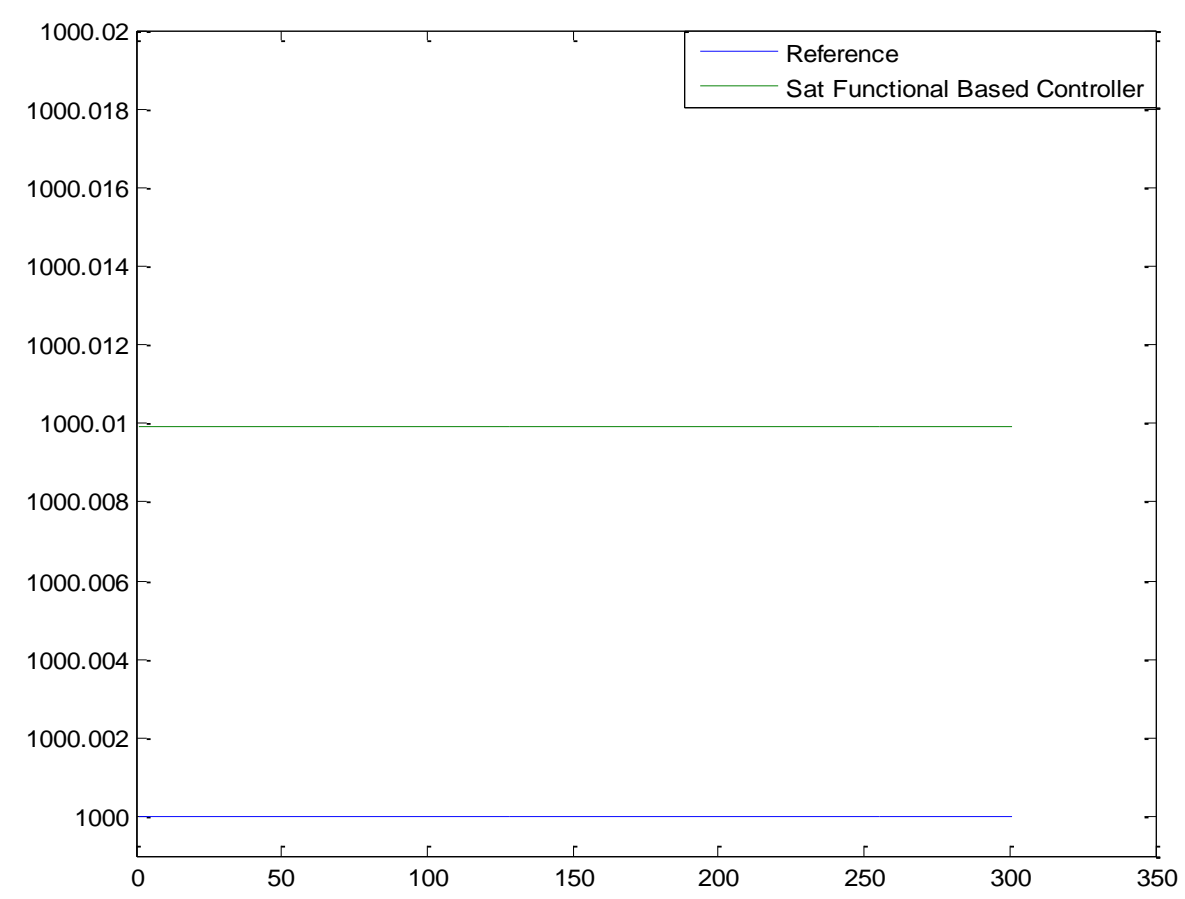

Figure 8. Engine Speed Test in IC Engine in Sat Functional Based Controller 
Figure 9, shows the error graph in saturation FBC with application to fuel ratio and Alfa. According to this Figure, both parameters have transient error but in steady state error point of view, both parameters have enough good response.

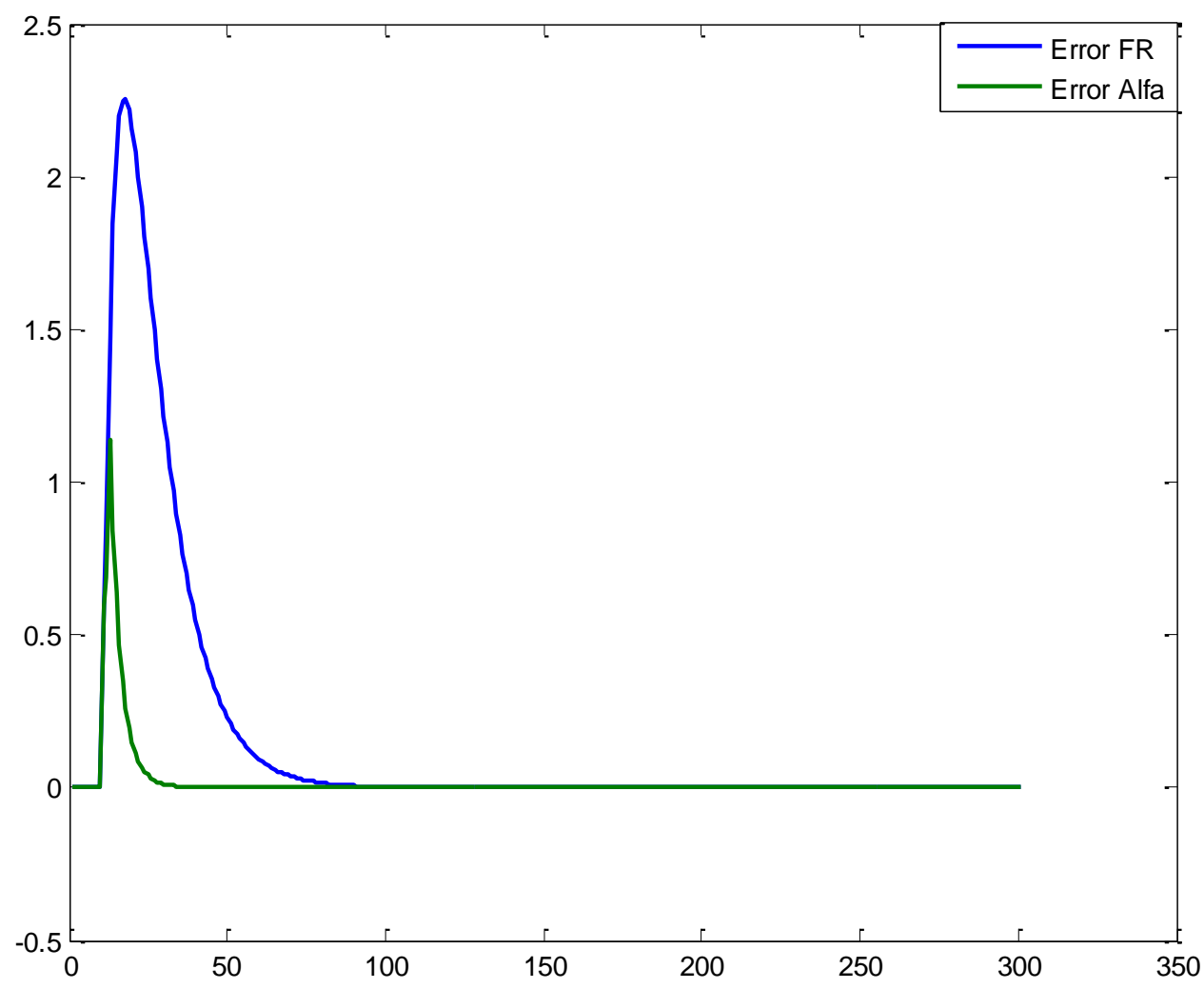

\section{Figure 9. Error Test in IC Engine in Saturation Functional Based Controller}

\section{Conclusion}

Smog hanging over cities is the most familiar and obvious form of air pollution. To reduce the challenge of smog hanging fuel ratio of IC engine plays an important role. To adjust the rate of fuel ratio three types of control techniques are introduced. Linear type PD controller, SIGN based functional based controller and SATURATION based functional based controller. However linear controller is used in many applications but it cannot guarantee the fuel ratio and ALFA performances of IC engine. The second choice to adjust the fuel ratio as well as ALFA is SIGN based FBC. However this technique have been reduced the error and improved the system's performance but it has two important challenges, high frequency oscillation and steady state error. To improve above challenges SATURATION based FBC have been used in this research. According to results and discussion, it can eliminate the high frequency oscillation as well as reduce the steady state error. In rise time point of view SIGN FBC has a better response compared with SATURATION FBC.

\section{Acknowledgements}

The authors would like to thank the anonymous reviewers for their careful reading of this paper and for their helpful comments. This work was supported by the Iranian Institute of Advance Science and Technology Program of Iran under grant no. 2014Persian Gulf-1C. 
Iranian center of Advance Science and Technology (IRAN SSP) is one of the independent research centers specializing in research and training across of Control and Automation, Electrical and Electronic Engineering, and Mechatronics \& Robotics in Iran. At IRAN SSP research center, we are united and energized by one mission to discover and develop innovative engineering methodology that solve the most important challenges in field of advance science and technology. The IRAN SSP Center is instead to fill a long standing void in applied engineering by linking the training a development function one side and policy research on the other. This center divided into two main units:

- $\quad$ Education unit

- $\quad$ Research and Development unit

\section{References}

[1] L. Horn and W. Pao and D. H. Johnson, "Chapter 89". In Longo, DL; Kasper, DL; Jameson, JL; Fauci, AS; Hauser, SL; Loscalzo, J.Harrison's Principles of Internal Medicine (18th ed.). McGrawHill. ISBN 0-07-174889-X, (2012).

[2] "Lung Carcinoma: Tumors of the Lungs", Merck Manual Professional Edition, Online edition. Retrieved, (2007) August 15.

[3] M. J. Thun, L. M. Hannan and L. L. Adams-Campbell, "Lung cancer occurrence in never-smokers: an analysis of 13 cohorts and 22 cancer registry studies", PLoSMedicine, vol. 5, no. 9, (2008) September.

[4] "Tobacco Smoke and Involuntary Smoking" (PDF). IARC Monographs on the Evaluation of Carcinogenic Risks to Humans (WHO International Agency for Research on Cancer), vol. 83. (2002). There is sufficient evidence that involuntary smoking (exposure to secondhand or 'environmental' tobacco smoke) causes lung cancer in humans. Involuntary smoking (exposure to secondhand or 'environmental' tobacco smoke) is carcinogenic to humans (Group 1).

[5] J. F. Cassidy, "On the Design of Electronic Automotive Engine Controls using linear Quadratic Control Theory," IEEE Trans on Control Systems, vol. AC-25, (1980) October.

[6] W. E. Powers, "Applications of Optimal Control and Kalman Filtering to Automotive Systems," International Journal of Vehicle Design, vol. Applications of Control Theory in the Automotive Industry, (1983).

[7] N. F. Benninger, "Requirements and Perfomance of Engine Management Systems under Transient Conditions," in Society of Automotive Engineers, (1991).

[8] N. F. Benninger, "Requirements and Perfomance of Engine Management Systems under Transient Conditions," in Society of Automotive Engineers, (1991).

[9] C. H. Onder, "Model-Based Multivariable Speed and Air-to-Fuel Ratio Control of an SI Engine," in Society of Automotive Engineers, (1993).

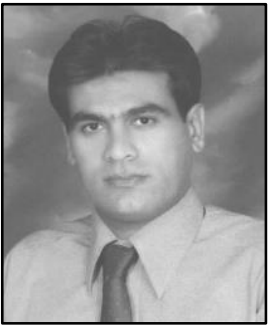

Amirzubir Sahamijoo, currently is senior research assistant at Institute of Advanced Science and Technology, Research Center, IRAN SSP. He is senior research assistant of team to Design Intelligent FPGA-Based Control Unit to Control of 4-DOF Medical Robot Manipulator since July, 2015 to now, research assistant of team (8 researchers) to design a Micro-electronic Based nonlinear controller for first order delay system since March, 2015 to now, research student ( 21 researchers) to design high precision and fast dynamic controller for multi-degrees of freedom actuator since 2014 to date, research student (9 researchers) to design Prevent the Risk of Lung Cancer Progression Based on Fuel Ratio Optimization since 2014 to date, and published 4 journal papers since 2014 to date. His current research interests are nonlinear control, artificial control system, Microelectronic Device, Internal Combustion Engine, and HDL design. 


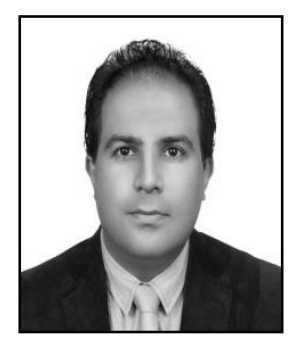

Farzin Piltan, is an outstanding scientist in the field of Electronics and Control engineering with expertise in the areas of nonlinear systems, robotics, and microelectronic control. Mr. Piltan is an advanced degree holder in his field. Currently, Mr. Piltan is the Head of Mechatronics, Intelligent System, and Robotics Laboratory at the Iranian Institute of Advanced Science and Technology (IRAN SSP). Mr. Piltan led several high impact projects involving more than 150 researchers from countries around the world including Iran, Finland, Italy, Germany, South Korea, Australia, and the United States. Mr. Piltan has authored or co-authored more than 140 papers in academic journals, conference papers and book chapters. His papers have been cited at least 3900 times by independent and dependent researchers from around the world including Iran, Algeria, Pakistan, India, China, Malaysia, Egypt, Columbia, Canada, United Kingdom, Turkey, Taiwan, Japan, South Korea, Italy, France, Thailand, Brazil and more. Moreover, Mr. Piltan has peer-reviewed at least 23 manuscripts for respected international journals in his field. Mr. Piltan will also serve as a technical committee member of the upcoming EECSI 2015 Conference in Indonesia. Mr. Piltan has served as an editorial board member or journal reviewer of several international journals in his field as follows: International Journal Of Control And Automation (IJCA), Australia, ISSN: 2005-4297, International Journal of Intelligent System and Applications (IJISA), Hong Kong, ISSN:2074-9058, IAES International Journal Of Robotics And Automation, Malaysia, ISSN:2089-4856, International Journal of Reconfigurable and Embedded Systems, Malaysia, ISSN:2089-4864. Mr. Piltan has acquired a formidable repertoire of knowledge and skills and established himself as one of the leading young scientists in his field. Specifically, he has accrued expertise in the design and implementation of intelligent controls in nonlinear systems. Mr. Piltan has employed his remarkable expertise in these areas to make outstanding contributions as detailed follows:Nonlinear control for industrial robot manipulator (2010IRAN SSP), Intelligent Tuning The Rate Of Fuel Ratio In Internal Combustion Engine (2011-IRANSSP), Design High Precision and Fast Dynamic Controller For Multi-Degrees Of Freedom Actuator (2013-IRANSSP), Research on Full Digital Control for Nonlinear Systems (2011-IRANSSP), Micro-Electronic Based Intelligent Nonlinear Controller (2015-IRANSSP), Active Robot Controller for Dental Automation (2015-IRANSSP), Design a Micro-Electronic Based Nonlinear Controller for First Order Delay System (2015-IRANSSP). The above original accomplishments clearly demonstrate that Mr. Piltan has performed original research and that he has gained a distinguished reputation as an outstanding scientist in the field of electronics and control engineering. Mr. Piltan has a tremendous and unique set of skills, knowledge and background for his current and future work. He possesses a rare combination of academic knowledge and practical skills that are highly valuable for his work. In 2011, he published 28 first author papers, which constitute about $30 \%$ of papers published by the Department of Electrical and Electronic Engineering at University Putra Malaysia. Additionally, his 28 papers represent about $6.25 \%$ 


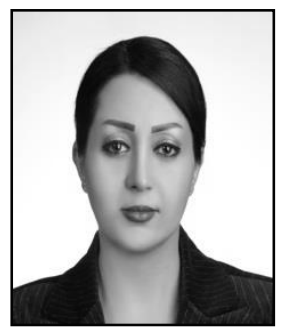

and $4.13 \%$ of all control and system papers published in Malaysia and Iran, respectively, in 2011.

Shahnaz tayebihaghighi, is currently research assistant at Institute of Advance Science and Technology, Research and Development Center, IRAN SSP. She is research assistant of team (47 researchers) to design and build of nonlinear control of industrial robot manipulator for experimental research and education and published 3 Papers in this field since 2010 to 2012, research assistant (9 researchers) to design and implement intelligent tuning the rate of fuel ratio in internal combustion engine for experimental research and education and published 1 Journal papers since 2011 to 20132015. Research assistant in project entitle: system modeling and identification Her current research interests are nonlinear control, artificial control system and applied to FPGA, system Identification and IC engine modeling and control.

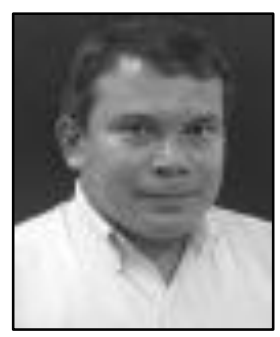

Nasri Sulaiman, is a Senior Lecturer in the Department Electrical and Electronic Engineering at the Universiti Purta Malaysia (UPM), which is one of the leading research universities in Malaysia. He is a supervisor and senior researcher at research and training center called, Iranian Institute of Advanced Science and technology (Iranssp) since 2012. He obtained his M.Sc. from the University of Southampton (UK), and Ph.D. in Microelectronics from the University of Edinburgh (UK). He has published more than 80 technical papers related to control and system engineering, including several co-authored papers with Mr. Piltan. He has been invited to present his research at numerous national and international conferences. He has supervised many graduate students at doctoral and masters level. $\mathrm{He}$ is an outstanding scientist in the field of Micro-Electronics. bDr. Nasri Sulaiman advisor and supervisor of several high impact projects involving more than 150 researchers from countries around the world including Iran, Malaysia, Finland, Italy, Germany, South Korea, Australia, and the United States. Dr. Nasri Sulaiman has authored or co-authored more than 80 papers in academic journals, conference papers and book chapters. His papers have been cited at least 3000 times by independent and dependent researchers from around the world including Iran, Algeria, Pakistan, India, China, Malaysia, Egypt, Columbia, Canada, United Kingdom, Turkey, Taiwan, Japan, South Korea, Italy, France, Thailand, Brazil and more.Dr. Nasri Sulaiman has employed his remarkable expertise in these areas to make outstanding contributions as detailed below:

- Design of a reconfigurable Fast Fourier Transform (FFT) Processor using multi-objective Genetic Algorithms (2008-UPM)

- Power consumption investigation in reconfigurable Fast Fourier Transform (FFT) processor (2010-UPM)

- Crest factor reduction And digital predistortion Implementation in Orthogonal frequency Division multiplexing (ofdm) systems (2011-UPM)

- High Performance Hardware Implementation of a Multi-Objective Genetic Algorithm, (RUGS), Grant amount RM42,000.00, September (2012-UPM) 
- Nonlinear control for industrial robot manipulator (2010-IRAN SSP)

- Intelligent Tuning The Rate Of Fuel Ratio In Internal Combustion Engine (2011-IRANSSP)

- Design High Precision and Fast Dynamic Controller For MultiDegrees Of Freedom Actuator (2013-IRANSSP)

- Research on Full Digital Control for Nonlinear Systems (2011IRANSSP)

- Micro-Electronic Based Intelligent Nonlinear Controller (2015IRANSSP)

- Active Robot Controller for Dental Automation (2015-IRANSSP)

- Design a Micro-Electronic Based Nonlinear Controller for First Order Delay System (2015-IRANSSP) 